\title{
E-GOVERNANCE IN PUERTO RICO: PERSPECTIVES FOR THE NEXT DECADE
}

\author{
Sandra Fonseca-Lind, Universidad Metropolitana, San Juan, PR, sfonseca3@suagm.edu \\ Mysore Ramaswamy, Southern University, Baton Rouge, LA, mysore@acm.org
}

\begin{abstract}
In today's highly demanding and time-limited working environment, access to information in a secure environment is expected not only from large corporations, small businesses and universities among other entities, but from the government as well. People no longer have time to spend waiting in long lines at agencies for conducting transactions at different government offices. The Commonwealth of Puerto Rico launched the PrStar.net state portal back in 1996, reengineered it and renamed it gobierno.pr in 2004, updated in 2007 and 2009. But to satisfy the needs and requirements of the citizens of Puerto Rico as well as international visitors, capacity needs had to be expanded. The objective is to convert the concept of the virtual office into reality. In this virtual office, the public can have access to general information and statistics. In addition, this serves as a single point for making transactions or requesting services from agencies without having to visit them. In this paper, we examine the evolution of the www.puertorico.gov portal since its initial inception back in 1996, its evolution to gobierno.pr and current state and we discuss the salient aspects of e-government implementation strategy that is suitable to the needs not only for government agencies but also to the citizens of Puerto Rico.
\end{abstract}

Keywords: E-Governance, E-Government, E-Readiness, Key Success Factors, Puerto Rico

\section{INTRODUCTION}

In today's highly demanding and time-limited working environment, access to information in a secure environment is expected not only from corporations, institutions and universities, but from the government. People no longer have time to spend waiting in long lines at agencies or government offices to receive services or benefits. Virtually all organizations, large and small, require an information technology application to conduct business. Those applications serve as the heart of their business, integrating with the rest of the operational units of the business, as well as reporting to higher management.

Traditionally, the interaction between a citizen or business and a government agency took place in a government office. With emerging information and communication technologies it is possible to locate service centers closer to the clients. Such centers may consist of an unattended kiosk in the government agency, a service kiosk located close to the client, or the use of a personal computer in the home or office. "E-Government" refers to the use by government agencies of information technologies (such as Wide Area Networks, the Internet, and mobile computing) that have the ability to transform relations with citizens, businesses, and other arms of government [5, 6]. These technologies can serve a variety of different ends: better delivery of government services to citizens, improved interactions with business and industry, citizen empowerment through access to information, or more efficient government management. The resulting benefits can be less corruption, increased transparency, greater convenience, revenue growth, and/or cost reductions. Analogous to e-commerce, which allows businesses to transact with each other more efficiently (B2B) and brings customers closer to businesses (B2C), e-government aims to make the interaction between government and citizens (G2C), government and business enterprises (G2B), and inter-agency relationships (G2G) more friendly, convenient, transparent, and inexpensive.

The Commonwealth of Puerto Rico launched the www.prstar.net state portal back in 1996, reengineered and renamed it www.gobierno.pr in 2004 and updated in 2007 and 2009 to its current name pr.gov. . But to satisfy the needs and requirements of the citizens of Puerto Rico as well as international visitors, capacity needs had to be expanded. The objective was to convert the concept of the virtual office into reality. In this virtual office the public can have access to general information and statistics. In addition, this serves as a single point for making transactions or requesting services from agencies without having to visit them. In Puerto Rico, there are no regulations or formal standards regarding information technology (IT) compliance for government agencies or small companies. But there are laws regarding electronic government standards and in the case of Puerto Rico, the Office 


\section{Issues in Information Systems \\ Volume 14, Issue 1, pp.207-214, 2013}

of Management and Budget is the designated entity to govern the information technology infrastructure of all government Information Technology (IT) installations.

With the passing of Law 151, Electronic Government Act of June 22, 2004, the objectives of having a centralized repository where all Puerto Rican citizens can access all services from the various agencies constituted one of the formal efforts to move the State of Puerto Rico's web page into to a dynamic portal and a virtual office. The Office of Management and Budget is an Agency of the Government of the Commonwealth of Puerto Rico created by law 147 of June 18, 1980 is the one in charge of managing the overall management standards and procedures to be followed by the Government Agencies of the Commonwealth of Puerto Rico, as well as managing the Government budget, expenses and investments.

Legal Framework for IT Infrastructure Governance in Puerto Rico was formalized with Executive letter 96-01 general guidelines and standards were approved and the Governors Committee for Information Technology was created. The thirteen (13) guidelines were revised and updated in 2004 and Law 151, Electronic Government Act was passed, also designating the Office of Management and Budget in charge of Government's Information Technology Governance. Among the general guidelines for information technology governance, the following are critical:

- Technological Resources Annual Management Plan

- Agency Web Site Design and Maintenance

- Information Systems Security

- Technology Services

- Management of Electronic Government Transactions

- Equipment and License Management

- Disposal of Equipment and Licenses

- Internet and Email Use

- Financial Systems Integration

- Standards for Computer Equipment Acquisition

- Best Practices for Technological Infrastructure

- Government Technology Acquisition Framework

Approved legislation regarding use of technological resources:

- Electronic Government Law

- Electronic Transactions Law

- Knowledge Management in Government Act

- Office of Management and Budget Law

- $\quad$ Puerto Rico Penalty Code of 2004

Some agencies are unaware of the existence of these documents, or are not following them as required, since no rule or law actually requires compliance like Sarbanes Oxley does to US major corporations [9]. In its annual progress report dated July, 2012, the Office of Management and Budget reported that in early 2009 the agency started working on the portal redesign with the objective of augmenting its processing capacity, with more online services, thus expanding the concept of the virtual government office. In order for the Puerto Rico Government Portal to be effective, more dynamism and functionality needs to be embedded. This paper is organized as follows. First we conduct a brief review of E-readiness issues. Then we look at the salient factors of e-government implementation strategy suitable to the needs not only for government agencies but to the citizens of Puerto Rico. Concluding remarks form the last section.

\section{E-READINESS ISSUES}

To ensure an effective strategy for e-government implementation, it is necessary that we analyze the e-readiness issues as they exist today. In this section, we study the following two critical components of e-society: digital infrastructure, and interaction content. Digital infrastructure refers to the mechanism through which users can access the cyberspace. Interaction content is what drives the users to go online. In the early stages, the Internet use relied on dial-up connections that offer limited capacity (56Kbps or less) and intermittent connectivity. The first generation of advanced services with continuous connectivity and expanded capacity (200Kbps to $1 \mathrm{Mbps}$ ) began to be deployed in the latter half of the 1990s. These include DSL services offered over telephone company copper wires, cable 
modem services offered over cable television facilities, and a small but growing number of wireless services (satellite and terrestrial). However, there are still significant portions of population who do not have access to these services.

Broadband Internet connectivity is viewed as an important part of the infrastructure required to ensure effective ecommerce. The Organization for Economic Cooperation and Development (OECD) states that as of December 2005, the number of broadband subscribers in the United States was 16.8\% (total subscribers: 49,391,060). The breakup is as follows: DSL: $6.5 \%$, Cable: $9.0 \%$, Other: $1.3 \%$. United States ranks $12^{\text {th }}$ among the industrialized countries in the list of broadband subscribers per 100 inhabitants. By ensuring high-speed access and 'always-on' connections, broadband technologies substantially change the patterns of Internet usage [8]. Moreover, whether many of these services should even be classified as 'broadband' has been questioned. The Federal Communications Commission (FCC) defines 'advanced services' as capable of providing more than $200 \mathrm{Kbps}$ on both directions. By that definition, many cable and DSL systems do not qualify, as they are constrained to upstream bandwidths of $128 \mathrm{Kbps}$ or less. At a mere four times the bit rate, $200 \mathrm{Kbps}$ represents only an incremental step from a dial-up modem. Much higher capacity access networks offering services in the 10s to 100s of Mbps (or more) per household will be needed to fully unleash the full potential of advanced communications infrastructure.

Local governments have the following two important roles to play in the development of broadband infrastructure: (i) financier and (ii) infrastructure developer [1]. Financial incentives can be aimed at stimulating supply, demand, or both. Subsidies to commercial providers can be in the form of outright grants, low-cost loans, or tax incentives. Subsidies to users are typically temporary in nature, or targeted at disadvantaged groups. For example, LaGrange, Georgia gave away WebTV equipment and service for a one year period in an attempt to get more of their socioeconomically citizens online [5]. Unfortunately, the attempt was largely unsuccessful, reflecting barriers to adoption that go beyond the cost of access, as well as unpopular limitations of the chosen technology - the WebTV devices used had no print capability. Broadband related subsidies appear to be more common at state and federal levels, where budgets are significantly large. For example, Pennsylvania administers a $\$ 3.3$ million digital divide grant program based on federal funds from the Temporary Assistance to Needy Families (TANF) program. One of their grants was $\$ 457,000$ to the Glendale School District (located in economically disadvantaged area) to extend wireless broadband Internet access from one school to neighboring schools as well as citizens, and to give laptops to community members who partake of training opportunities [8].

The other strategy that local governments can pursue to stimulate broadband is to develop one or more aspects of the necessary infrastructure themselves. Based on an assessment of the communications needs and existing resources available to different groups of users, government can prioritize infrastructure developments for itself, local businesses, and citizens. A local government can deploy a network for its own needs, and later exploit any excess capacity to offer services to nearby businesses.

Wireless networks add their own complexity to the mix. Last year, Google while testing its first municipal Wi-Fi network in its hometown, Mountain View, Calif., using transmitters attached to street lamps, observed that people using Google's network could get online at home only by holding their laptops against a window. This was to be expected as using municipal Wi-Fi for residential coverage was "the equivalent of expecting street lamps to light everyone's homes."

The second critical component of e-society refers to the digital content that users can access User interactions with digital or electronic means have been grouped in a number of ways [11]. In the present analysis, it will be useful to categorize them in the following way: information services, communication services, and transaction services. A more inclusive e-society has to provide more useful digital interactions to a larger segment of the society, especially in the third category of transaction services.

In the context of e-inclusion, under the category of transaction services, government-to-citizen interactions of eGovernment become very significant. In order to build a more inclusive e-society, we need to address these questions:

- How can we make e-Government truly citizen-centric?

- Do we have objectives that are correct and realistic?

- How well are we achieving these objectives fully and cost effectively? 
- Are these objectives jointly determined and agreed upon by the citizens and the government agencies? We need better models of the processes used to plan, fund, develop, implement, operate, and evaluate successful eGovernment in various political and social, cultural, and economic contexts [1].

The e-Governance cube addresses some of the above concerns. Ramaswamy and Selian [26] propose the formation of an e-Governance cube with the following three axes: entity type on the $\mathrm{x}$-axis, processing complexity on the $\mathrm{y}$ axis, and perceived value on the z-axis. The e-governance cube provides a means of evaluating an extensive (if not comprehensive) series of government-constituent interactions. Depending upon which of the 27 sub-cubes contains the given transaction of interest, we are now able to make inferences on the potential of that transaction for its ease of conversion to e-governance. This naturally opens up a wide arena of analysis, particularly for others who wish to specialize and focus specifically on the dynamics and characteristics of specific e-governance transactions. In the context of the e-governance cube model, the further one moves away from the origin, the more resistance one encounters. From the e-inclusion view point, the processes that are valued high on the z-axis (perceived value) need to be addresses first.

Although technology can create new or modified business practices at a rapid rate, successful adoption of new best practices must stand up to market forces. Technology and the marketplace are continually reshaping business activities and as a consequence, business strategies. An organization must continually work towards an alignment that fits into the organization's business strategy, IS strategy, ethical advancement and compliance strategies. This alignment should improve the likelihood that IS initiatives are explicitly linked to areas that are critical to successful business performance, provide a source of competitive advantage and ensure ethical compliance. The process of aligning strategies should heighten management's awareness and use of information systems to better support organizational goals, objectives, and ethical compliance. The role of IS should be that of a strategic enabler for competitive success, rather than just an operational supporter.

\section{E-GOVERNMENT DEVELOPMENT STRATEGY FOR THE NEXT DECADE}

Although the Puerto Rico Government has a portal www.gobierno.pr and www.pr.gov, it still is most informationbased only. Even though some basic transactions can be made through the portal, still it is far from being a virtual office. Most of the agency's portals are still information-based only- The first part of the descriptive research will consisted on historic investigation of the first portal developed back in the 1990's www.prstar.net. The current efforts with the www.gobierno.pr portal and its overall functionality were thoroughly assessed. Usability guidelines were used to perform this analysis.

The question formulated for this research was to evaluate whether there is a suitable electronic portal where all citizens not only residents of Puerto Rico but the International Community can gather enough information as well as perform basic government transactions from one single point. Among the various activities done during the research was the assessment and analysis of the current state of controls and overall information systems security in the portal of the Commonwealth of Puerto Rico. When seen from a functional perspective, the e-government portal should be a seamless integration of services offered by the government agencies as shown in Appendix I. This would require massive back office integration of data storage and authentication standards.

\begin{tabular}{|c|c|c|}
\hline & Physical Expression & Abstract Expression \\
\hline $\begin{array}{c}\text { Not Revalorized } \\
\text { in Use }\end{array}$ & Infrastructural Capital & Environmental Capital \\
\hline $\begin{array}{c}\text { Revalorized } \\
\text { In Use }\end{array}$ & Human Capital & Social Capital \\
\hline
\end{tabular}

Figure 1. Taxonomic Foundations of Four Capitals (Adapted from [14])

E-government implementation strategy for Puerto Rico has to be developed by focusing on the following two considerations. First, the resources that are available for installing an ICT enabled system for citizen-government interactions. Second, an assessment of the public value of ICT enabled governance. The 4-Capitals Framework as applied to the e-government domain is considered for the first part of analysis. The four capitals are Infrastructural Capital, Environmental Capital, Human Capital, and Social Capital. Infrastructural capital consists of computing and communications hardware and systems level software deployed along with the documentation that supports it. The 


\section{Issues in Information Systems \\ Volume 14, Issue 1, pp.207-214, 2013}

Internet and related communications modalities (email, video and webcams, etc.) constitute environmental capital. Human capital comprises technical skills needed to develop, configure, and maintain the ICT infrastructure together with organizational governance mechanisms and skills needed by users. Social capital refers to bonding and trust developed among the different tiers of users of the system. Figure 1 illustrates how these four capitals are interconnected with reference to ICT enabled systems.

The above four forms of capital give rise to six binary relations between them. Architectural design which links infrastructural capital and environmental capital addresses the issues related to marrying ICT infrastructure to satisfy functional design requirements. Connectivity which links infrastructural capital to social capital has to ensure that the configuration of infrastructural components is supported by the technological infrastructure. Communicative mediation that links environmental capital and social capital identifies the modes of communication that are to be supported and the related issues of privacy and security needed to promote and sustain trust. System management which links infrastructural capital and human capital seeks to suitably match the system technology with the skills and competencies of people involved in its configuration, management, and administration. Relational conduct which links human capital and social capital seeks to ensure that the people and organizations involved are equipped to conduct proper interactions; for example, do they have sufficient skills in electronic communication. Affordable design which links environmental capital and human capital pertains to the design of the communicative interface to support the selected modes of communication in ways that reflects both the attainable technological skills and competencies of the ordinary user.

The objective of 'E-inclusion' is to end the digital divide, a term used to describe the fact that the world can be divided into people who do and people who don't have access to - and the capability to use - modern information technology (IT). According to advocates, e-inclusion has the power to: close the gap between developed and less developed countries; promote democracy and mutual understanding; and empower disadvantaged individuals, such as the poor, the disabled, and the unemployed.

An increasing number of computer equipment and software companies have e-inclusion programs. According to Hewlett-Packard, the purpose of their e-inclusion initiative is "... to close the gap between the technologyempowered communities and the technology-excluded communities on our planet by making it profitable to do so." The company's program is targeting low-income areas in the developing world to improve opportunities for education, healthcare, and employment and deliver access to world markets and consumer credit.

Recent studies of the digital divide confirm that the user education and skills are discriminating factors in the use of e-services. They also indicate that the 'access divide' is narrowing $[8,17]$. The effective use of e-services relies on relies on cumulative skills developed through the use itself (cognitive and social resources). The 'second order' digital divide refers to the ability to deal with continuous evolution and changing complexity of e-services.

To attract technology shy or resistant people, awareness campaigns should be expanded in communities at risk of digital exclusion, communicating the specific benefits for disadvantaged people, and using channels that are appropriate for their way of life. Awareness measures should be designed as a first step in an integrated e-inclusion strategy, followed-up by incentives for access and training. Information and communication technology (ICT) producers, information providers and government authorities should be sensitized to the special needs of disadvantaged people in terms of ICT equipment and online content and in terms of opportunities for removing barriers for work.

Some of the other broad range issues emerging in the context of e-inclusion are:

- Demand-related issues such as lacking motivation among particular population groups to utilize online services for one's own improvement;

- Supply-oriented issues such as lack of recognition of specific requirements certain population groups may have with the services offered;

- Regulation-related issues such as restricted availability of the required technical infrastructure (access networks, terminals) among particular population groups.

Information Society Commission in their recent report indicates that the following factors as critical in developing a successful e-government: Centrality of the Citizen, Efficiency Gains, Restructuring of Administrative Processes, 
Modernization Link, Statistical and Spatial Data, and Innovative Delivery Models. The centrality of the citizen is the key concept in designing e-government structure. Modern technologies have the potential to create seamless, responsive and citizen-centric government for the benefit of all. This can free the citizen from the need to understand the complex structures of government in order to be able to deal effectively with it. This also requires that government embrace the concept of a single integrated delivery channel that enables the citizen to access the exact information or government service required. By providing quality service, promoting transparent and accountable government, and enabling the citizen to engage with the public policy process, e-government helps build trust between the citizen and government. Such trust is an essential factor in giving people the confidence to use online systems. E-government can harness modern technology to enable departments achieve efficiency improvements in the processing of large volumes of data and other administrative operations. There is scope for even greater efficiencies through greater sharing of processes within and between departments.

It is a misconception to imagine that e-government is merely an automation of existing government services; it is a radical convergence of government and technology that has the potential to radically transform the public service and the citizen's experience of it. This convergence requires a major reorganization of administrative processes. In that sense, e-government is more about government than about ' $\mathrm{e}$ '. This sharing of processes promotes a more horizontal form of organization than the traditional vertical approach where each department or agency acts autonomously. New connections are forged between agencies in the public sector and also between government and citizen. The modernization of the public service is closely connected to the e-government process and shares many of the same goals such as provision of better quality service, focus on the citizen, more efficient and effective work practices, and improved decision making. E-government provides the tools which enable the modernization process to be wide ranging and effective. In the traditional bureaucratic model, each department is organized on hierarchical lines with its own legislative basis, budget, rules, structures, processes, and attributes. Despite this silo approach, government departments have a huge amount in common. E-government forces the aggregation of common services which benefits both the government agencies and the general public.

Government departments collect vast amounts of data. These are held in a wide variety of independent datasets with no recognition of the duplicate nature of much of that data. A substantial amount of data is geospatial in character. Implementing a spatial referencing system into e-government will improve the efficiency. It is no secret that it is very difficult to complete major Information and Communication Technologies (ICT) programs on time and within budget. We need to find innovative delivery models in cooperation with the private sector. The advantage for the government would be that the private sector would provide the infrastructure and carry the risk and most of the upfront cost [27]. In return, the private sector would receive payment from resultant savings. It is important that a competent and reliable private sector partner is selected and that the pricing structure is such that this partner received a reasonable, but not excessive, rate of return. The benefit to the citizen would be an improved service, greater choice, and value for money.

\section{CONCLUSIONS}

A sound strategy has to strengthen the initial steps towards e-governance in Puerto Rico and develop future action plans to consolidate the benefits. To develop such a plan, we have taken a comprehensive look starting from the beginning of government portal. The four capitals model indicates which areas have to be strengthened. The critical success factors as stated in the Information Society Report guides us regarding the various aspects of e-government and how it can be implemented in a phased manner with the cooperation of private sector. It is essential that efforts be made to reduce risk factors by conducting business process engineering (BPR) before actually considering automating any government-citizen interaction. Due to their limited resources, local governments may not be able to or need to develop their own portal systems. They can be part of state-wide portals, providing seamless and integrated government service to the citizens.

In addition, it is necessary that the overall strategy includes antidotes, figuratively speaking, to the following symptoms: a general reluctance to experiment with e-based methods of delivery; a tendency to find reasons for inaction and for exaggerated risk-averse behavior on the Internet and Web issues; an unwillingness to divert resources from established ways of doing things to developing Internet based communications and transactions; a 


\section{Issues in Information Systems \\ Volume 14, Issue 1, pp.207-214, 2013}

tendency to regard putting services on the Internet as something that must be added on to all the activities that the agency does already; and an attitude that no e-government innovation can be responsibly entered into until the clearest possible financial case for it can be made. Mandate is necessary to overcome resistance in the public sector which may be especially unresponsive to technology-driven change. To be effective, mandate needs to come from higher-up. Local organizations need to ensure the potential adopters have the required infrastructure and training to adopt e-government.

\section{REFERENCES}

1. Allison, Juliann Emmons. (2002) Technology, Development, and Democracy: International Conflict and Cooperation in the Information Age. Albany: State University of New York Press.

2. Al-Mashari, Majed, Zahir Irani, \& Mohamed Zairi. (2001). Business process reengineering: a survey of international experience. Business Process Management Journal, December 2001, pp. 437-455.

3. Alter, S. (2002) Information Systems: Foundations of E-Business. Prentice Hall, Upper Saddle River, NJ.

4. Berghel. Hal. (2005). The Two Sides of ROI. Return on Investment Vs. Risk of Incarceration. Communications of the ACM. 48.4. pp. 15-20.

5. Carbo, T. and Williams, J. (2004). Models and Metrics for Evaluating Local Electronic Government Systems and Services. The Electronic Journal of Electronic Government, Vol. 2, No. 1, pp. 99-106.

6. Carbo, T. and Williams, J. G. (2004). "Some Determinants of User Perceptions of Information Quality on the World Wide Web," Electronic Journal of e-Government, Vol. 2, No. 2 pp. 94-105.

7. Choi, S. et al. (1997). The Economics of Electronic Commerce, Macmillan Technical Publishing, Indianapolis.

8. Clark, K. and Baker, P. (2003). Municipal Advanced Telecommunication Infrastructure Project (MuniTIP). Georgia Center for Advanced Telecommunications Technology, OTP Policy Study No. 50103.http://www.gcatt.org/otp/papers/ MuniTIP.pdf

9. Fonseca-Lind, S et al (2008), Indirect Consequences of Sarbanes Oxley on IT Governance in Puerto Rico, IABPAD Proceedings, pp. 528-538.

10. Fountain, Jane E. (2001) Building the Virtual State: Information Technology and Institutional Change. Washington, DC: Brookings Institution Press.

12. Government Technology. (2002). Pennsylvania Targets Digital Divide. http://www.govtech,net/news.news.phtml?docid=2002.1209.33355

11. Grimaila, Michael, R. Kulkarni, Abhijit, S. (2005). Challenges is Achieving Sarbanes-Oxley Compliance. The ISSA Journal. February, 2005.

13. Grimsley, M, Meehan, A, Sen Gupta, K (2006) Evaluative Design of e-Government Projects: A Public Value Perspective. Proceedings of the Twelfth Americas Conference on Information Systems, Acapulco, Mexico August $04^{\text {th }}-06^{\text {th }} 2006$.

14. Grimsley, M, Meehan, A, Tan, A, (2005) Capital Accounting: Evaluating e-Government projects from a community development perspective. Z. Irani, T. Elliman and O.D. Sarikas (Eds.) Proceedings of the eGovernment Workshop '05 (eGOV05), Brunel University, UK, 13th Sept. 2005. ISBN 1-902316-46-0

15. Heeks, R (2003). "Causes of eGovernment Success and Failure: Design Reality Gap Model," http://www.edevexchange.org/ eGov/ causegap.htm

16. Homburg, V. and Bekkers, V. (2002) "The Back-Office of E-Government," Proceedings of the $35^{\text {th }}$ Hawaii International Conference on Information Systems, (9 pages).

17. Keil, M. et al. (2003). Bridging the Digital Divide: The Story of the Free Internet Initiative in LaGrange, Georgia. Proceedings of the $36^{\text {th }}$ Hawaii International Conference on Information Systems, (10 pages).

18. Kendall, K. E. \& Kendall, J. E., (2002), System Analysis and Design, $5^{\text {th }}$ Ed., Prentice Hall.

19. Koss, F. A. (2001). The Challenges of redressing the digital divide, Journal of International Affairs, 55 (1), 75-90.

20. Kuzmin, A. (2003). "The Two Dimensions of e-Government: Potential and Use," www.processconsulting. ru/doc/ Two_dimensions_of_e-Government.pdf

21. Lee, $\mathrm{H}$. et al (2003). The growth of broadband and electronic commerce in South Korea: Contributing factors, Information Society, 19 (5), 81-93.

22. Mason, S. M. et al (2003). Applying communication theory to digital divide research, IT and Society, 1 (5). 


\section{Issues in Information Systems \\ Volume 14, Issue 1, pp.207-214, 2013}

23. McLeod, R. and Schell, G. (2001) Management Information Systems. Prentice Hall, Upper Saddle River, NJ.

24. Mistry, J. J. (2005). A conceptual framework for the role of government in bridging the digital divide, Journal of Global Information Technology Management, 8 (3), 28-46.

25. Naarmala, J. (2004). "Going Digital - Explaining Dimensions of eGovernment," www.ebrc.info/ pages_ C86FCC04-3314-4DF9-9AE2-138286 0CB17F.asp

26. Ramaswamy, M and Selian, A. (2007). e-Government in Transition Countries: Prospects and Challenges, Proceedings of the $40^{\text {th }}$ Hawaii International Conference on Information Systems, (10 pages).

27. Scholl, H. J. (2003) "E-Government: A Special Case of ICT-enabled Business Process Change," Proceedings of the $36^{\text {th }}$ Hawaii International Conference on System Sciences, (12 pages).

28. Turban, Ephraim. McLean, James. (2002). Information Technology for Management - Transforming Business in the Digital Economy. $3^{\text {rd }}$. Ed. John Wiley \& Sons.

29. Wimmer, M. R. et al (2001) "Electronic Business Invading the Public Sector: Considerations on Change and Design" Proceedings of the $34^{\text {th }}$ Hawaii International Conference on System Sciences, (10 pages).

30. Zmud, R. W. (1978) "An Empirical Investigation of the Dimensionality of the Concept of Information," Decision Sciences (9), pp. 187-195. 